\title{
Physical, Mechanical, Thermal and Morphology Properties of Biodegradable Polymer Nanocomposites and Its Comparison
}

\author{
Md. Rezaur Rahman ${ }^{1, a}$, Josephine Lai Chang Hui ${ }^{1}$ and Sinin Hamdan ${ }^{2}$ \\ ${ }^{1}$ Department of Chemical Engineering and Energy Sustainability, Faculty of Engineering, Universiti Malaysia Sarawak, 94300, Kota \\ Samarahan, Sarawak, Malaysia. \\ ${ }^{2}$ Department of Mechanical and Manufacturing Engineering, Faculty of Engineering, Universiti Malaysia Sarawak, 94300, Kota Samarahan, \\ Sarawak, Malaysia.
}

\begin{abstract}
Polyvinyl alcohol (PVA) and Polylactic acid (PLA) were fabricated with the addition of nanofiller such as nanoclay and fumed silica through suitable technique namely solution intercalation film casting. These nanocomposites undergo Fourier transform infrared spectroscopy, scanning electron microscopy, tensile test and thermogravimetric analysis. FT-IR results showed that both nanocomposites were well intercalated with fumed silica and clay with the reduction of hydroxyl groups. From SEM results, it proved that clay $1.28 \mathrm{E}$ is more suitable to be intercalated with PLA matrix while clay $1.30 \mathrm{E}$ is more suitable to be introduced into PVA matrix. The addition of both nanofillers improved the tensile properties of the nanocomposites. TGA results showed that polyvinyl alcohol/fumed silica/clay (PVA/fsi/clay) had better thermal stability compared to polylactic acid/fumed silica/clay (PLA/fsi/clay) nanocomposites. Both nanocomposites are applicable in the biomedical field.
\end{abstract}

\section{Introduction}

The great improvement of the thermal and mechanical properties on the polymer nanocomposites leads them to be widely applied in many fields such as paper coating, articular cartilage, thickener materials in paints, detergent and adhesives due to its with excellent biocompatibility and attractive properties [1-2].

Biodegradable polymers such as polyvinyl alcohol (PVA) and polylactic acid (PLA) were greatly applied to form nanocomposites. PVA is prepared using the polymerization of vinyl acetate followed by alcoholysis while PLA is linear aliphatic polyester [3]. However, pure PVA and PLA had poor physical and mechanical properties [4]. Therefore, both polymer matrices should be deeply improved by introducing various types of filler.

Nowadays, nanofiller such as fumed silica and nanoclay were introduced into polymer matrix to enhance the properties of the nanocomposites. Fumed silica particles usually exist in a form of fine powder or colloid suspension. It was embedded in a polymer matrix for its large surface area and smooth nonporous surface [5]. For nanoclay, it is defined as a class of materials made up of layered silicates. Montmorillonite (MMT) was one of the common nanoclay that was introduced into polymer matrix to improve the physical and mechanical properties of nanocomposites [6].

The $\mathrm{Na}$ ion-exchanged clay was easily dispersed into PVA matrix which significantly enhanced the thermal and mechanical properties [7]. Besides, the solvent casted PVA/clay nanocomposites showed better surface

\footnotetext{
a Corresponding author: rmrezaur@feng.unimas.my
}

morphology and stronger polymer-clay bonding that reduced water absorption [8]. Addition of fumed silica into PVA matrix improved the thermal degradation of the PVA/fumed silica nanocomposites [9]. Besides, incorporation of clay into PLA matrix enhanced the thermal stability of the nanocomposites by increasing the glass transition temperature consistently [10]. Sol-gel PLA/fumed silica nanocomposites were fabricated which improved the tensile properties as well as the thermal degradation with the introduction of fumed silica [11]. In addition, the fumed silica was incorporated into PLA matrix to improve the tensile strength and thermal stability of the nanocomposites [12].

In this present work, solution-intercalation and solution-intercalation film-casting technique were used to produce $\mathrm{PVA} / \mathrm{fsi} /$ clay and $\mathrm{PLA} / \mathrm{fsi} /$ clay nanocomposites respectively using different two types of clays $(1.28 \mathrm{E}$ and 1.30E). Physical, mechanical, thermal and morphological properties of nanocomposites were investigated. The compatibility of the clays towards the polymer matrices was also investigated.

\section{Methodology}

\subsection{Materials}

The silica powders used in this study was obtained in a mesh size of 8 microns which is white to off-white in colour. The chemicals used polyvinyl alcohol (PVA), polylactic acid (PLA), Nanoclay, Nanomer 1.28E and 
1.30E were supplied by Sigma-Aldrich. Nanomer $1.28 \mathrm{E}$ is montmorillonite clay surface was modified with 25-30 wt.\% trimethyl stearyl ammonium. Nanomer $1.30 \mathrm{E}$ is montmorillonite clay was surface modified with 25-30 wt.\% octadecylamine. The bulk density of both clays was 200 to $500 \mathrm{~kg} / \mathrm{m} 3$ and average particle size was around 20 microns.

\subsection{Methods}

\subsubsection{Preparation of PVA nanocomposites by solution intercalation}

The PVA/fsi/clay nanocomposites were prepared as shown in Table 1. Silica was dried at 200 for 48 hours in a vacuum oven. PVA and clay were dried at 50 and 60 respectively for 24 hours in a vacuum oven. The samples were prepared in a deionized water/methanol (3:1) solvent mixture. The mixtures were first stirred at 70 for 24 hours. The homogeneous solutions were then ultrasonicated in an ultrasonic bath at room temperature for 1 hour. The solid films were produced by casting a sample onto a glass mold by slowly evaporating the solvent in air for 3 days. The films with a thickness of $\sim 150 \mathrm{~m}$ were put in a vacuum oven at 50 for 24 hours in order to get rid of the extra solvent. The dried films were stored in desiccators prior to characterization [13].

\subsubsection{Preparation of PLA nanocomposites by solution intercalation film-casting}

The PLA/fsi/clay nanocomposites were prepared as shown in Table 1. PLA was dissolved in dichloromethane. Dichloromethane was added into four types of clay in four separated beakers to form clay dispersions. Both the PLA solution and clay suspension were ultrasonicated separately for $30 \mathrm{~min}$ with an ultrasonicator at room temperature and subsequently mixed. Fumed silica was added before the final mixture was further sonicated for $30 \mathrm{~min}$. The mixture was then casted on a glass surface and kept in vacuum oven for controlled evaporation of the solvent for 2 days. The clear nanocomposite films with thickness ranging from 500 to $700 \mathrm{~m}$ were obtained and subsequently dried at 80 under vacuum for 2 days. The nanocomposites were kept in desiccator for further characterizations and analysis [14].

Table 1. Preparation of PVA/fsi/clay and PLA/fsi/clay nanocomposites

\begin{tabular}{|c|c|c|}
\hline $\begin{array}{c}\text { Amount of } \\
\text { PVA/PLA (g) }\end{array}$ & $\begin{array}{c}\text { Amount of fumed } \\
\text { silica (g) }\end{array}$ & $\begin{array}{c}\text { Amount (g) and } \\
\text { type of clay }\end{array}$ \\
\hline 27.00 (PVA) & 2.50 & $0.50(1.28 \mathrm{E})$ \\
\hline 27.00 (PVA) & 2.50 & $0.50(1.30 \mathrm{E})$ \\
\hline 24.45 (PLA) & 0.05 & $0.50(1.28 \mathrm{E})$ \\
\hline 24.45 (PLA) & 0.05 & $0.50(1.30 \mathrm{E})$ \\
\hline
\end{tabular}

\subsection{Microstructural Analysis}

\subsubsection{Fourier Transform Infrared Spectroscopy (FT- IR)}

The infrared spectra of the monomer systems were recorded on a Shimadzu IRAffinity-1. The transmittance range of the scan was 700 to $4000 \mathrm{~cm}-1$ [13-14].

\subsubsection{Scanning Electron Microscopy}

The interfacial bonding between the PVA or PLA matrices, clay and fumed silica were examined using a scanning electron microscope (SEM) (JSM-6710F) supplied by JEOL Company Limited, Japan. The specimens were first fixed with Karnovsky's fixative and then take through a graded alcohol dehydration series. Once dehydrated, the specimen was coated with a thin layer of gold before being viewed microscopically. The micrographs were taken at magnifications ranging from 250 to 1500 [13-14].

\subsubsection{Tensile Testing}

Mold shape thin films were cut with a rectangular die and tested in a AG-X Plus Series Precision Universal Testers (300kN Floor Model) supplied by Shimadzu Corporation at room temperature. The gauge length, width and thickness of the samples were 15,2 and 0.15 $\mathrm{mm}$ respectively. The cross head speed used was $1 \mathrm{~mm} / \mathrm{min}$. The quoted results were averaged over at least five specimens [13-14].

\subsubsection{Thermogravimetric Analysis (TGA)}

Thermogravimetric analysis (TGA) measurements were carried out on $5-10 \mathrm{mg}$ of both $\mathrm{PVA} / \mathrm{fsi} / \mathrm{clay}$ and $\mathrm{PLA} / \mathrm{fsi} /$ clay nanocomposites at a heating rate of $10 / \mathrm{min}$ in a nitrogen atmosphere using a Thermogravimetric Analyzer (TA Instrument SDT Q600). Thermal decomposition of each sample occurred in a programmed temperature range of 0 to 700 . The continuous weight loss and temperature were recorded and analysed [13-14].

\section{Results and Discussion}

\subsection{Fourier Transform Infrared Spectroscopy (FT-IR) Analysis}

The IR spectra of PVA/fsi/clay and PLA/fsi/clay nanocomposites were shown in Figure 1. The characteristic peaks between $1100-1000 \mathrm{~cm}-1$ was attributed to $\mathrm{v}(\mathrm{Si}-\mathrm{O}-\mathrm{Si})$ respectively [15]. The characteristic band $1650 \mathrm{~cm}-1$ was attributed to $\mathrm{v}(\mathrm{C}=\mathrm{C})$ [16]. Besides, the peaks between 3500 and $3000 \mathrm{~cm}-1$ are mainly related to hydroxyl groups. From Figure 1(a-b), the IR spectrum of PVA/fsi/clay (1.28E) nanocomposite was broader compared to $\mathrm{PVA} /$ fsi/clay (1.30E) nanocomposite. This was due to the side chained-silica particles hampered the hydrogen bonds linkage in the 
PVA chains. In addition, the amplitudes of $\mathrm{Si}-\mathrm{O}-\mathrm{Si}$ are increased compared to the original silica nanoparticles due to the intercalation between the PVA matrix with the clay and fumed silica.

Apart from that, Figure 1(c-d) presented the FT-IR spectra of PLA/fsi/clay (1.28E) and PLA/fsi/clay (1.30E) nanocomposites. PLA/fsi/clay (1.28E) nanocomposite showed broader peaks at $1080 \mathrm{~cm}-1,1450 \mathrm{~cm}-1,1750 \mathrm{~cm}-$ 1 and $2946 \mathrm{~cm}-1$ compared to PLA/fsi/clay $(1.30 \mathrm{E})$ nanocomposite. The IR peak at $1080 \mathrm{~cm}-1$ was associated with silanol groups which overlapped by the bands at $1042 \mathrm{~cm}-1$ of $\mathrm{C}-\mathrm{O}-\mathrm{C}$ and $\mathrm{C}-\mathrm{CH} 3$ of PLA. This was attributed to the $\mathrm{C}-\mathrm{O}$ stretching vibrations that impeded in this region [17]. Another strong absorption band at $1750 \mathrm{~cm}-1$ was corresponded to the $\mathrm{C}=\mathrm{O}$ stretching vibration as detected in Figure 1(d) [18]. Moreover, the peak at $2946 \mathrm{~cm}-1$ was also visibly detected in Figure $1(\mathrm{~d})$ assigned to the $-\mathrm{CH}$ groups in PLA [19].

From this result, it was successfully proved that both PVA and PLA matrices were compatible with fumed silica and clay. Besides, this result could concluded that clay (1.28E) was more compatible to be introduced into PLA/fsi matrix compared to clay $(1.30 \mathrm{E})$ while clay (1.30E) was more compatible to be introduced into $\mathrm{PVA} /$ fsi matrix compared to clay (1.28E).

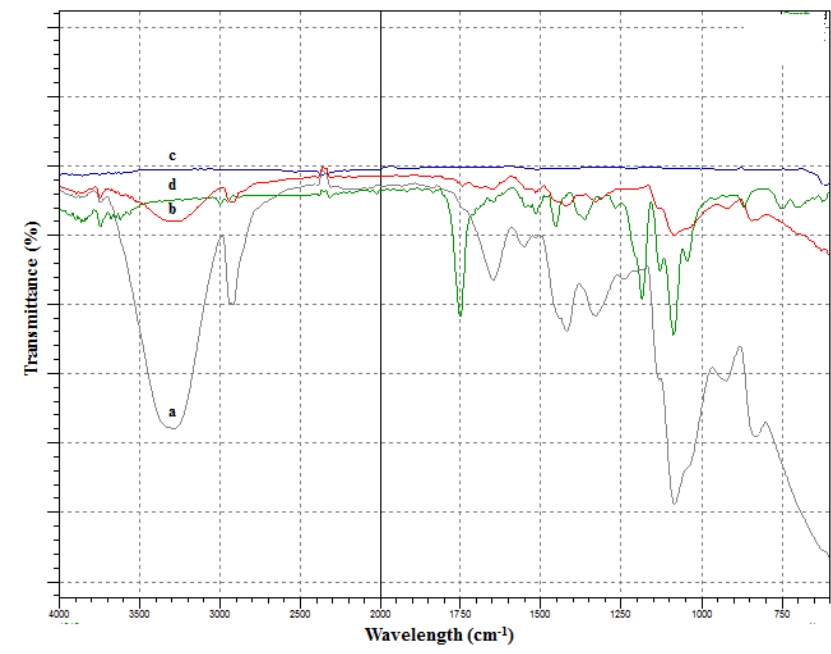

Figure 1. FT-IR spectra of (a) PVA/fsi/clay (1.28E) nanocomposite, (b) PVA/fsi/clay (1.30E) nanocomposite, (c) PLA/fsi/clay (1.28E) nanocomposite and (d) PLA/fsi/clay (1.30E) nanocomposite.

\subsection{Surface Morphology}

The SEM micrographs of PVA/fsi/clay and PLA/fsi/clay nanocomposites were shown in Figure 2(ad). The uniform surface of PVA-si-clay (1.28E) nanocomposites in Figure 2(a) indicated better compatibility among the PVA/fsi with clay. Figure 2(b) showed that PVA/fsi/clay (1.30E) nanocomposite was dispersed unevenly with the presence of agglomeration due to high surface energy and poor adhesion between clay and PVA/fsi matrix [20]. Besides, it was found that $\mathrm{PLA} /$ fsi/clay (1.28E) nanocomposite appeared to have uniform and homogeneous dispersion without aggregation of fumed silica and clay [21]. This proved that PLA/fsi matrix had strong covalent bond with clay (1.28E). Figure 2(d) presented that PLA/fsi/clay (1.30E) nanocomposite showed uneven surface due to the nonhomogeneous particle distribution.

From Figure 2, it was clearly showed that clay (1.28E) had great compatibility with PLA/fsi matrix while clay (1.30E) showed better compatibility with $\mathrm{PVA} /$ fsi matrix as there was no aggregation formed at the surface of PVA/fsi/clay (1.30E) and PLA/fsi/clay (1.28E) nanocomposites. The strong interfacial bonding between $\mathrm{PVA} /$ fsi/clay (1.30E) and PLA/fsi/clay (1.28E) nanocomposites was reflected in the higher mechanical and thermal properties.
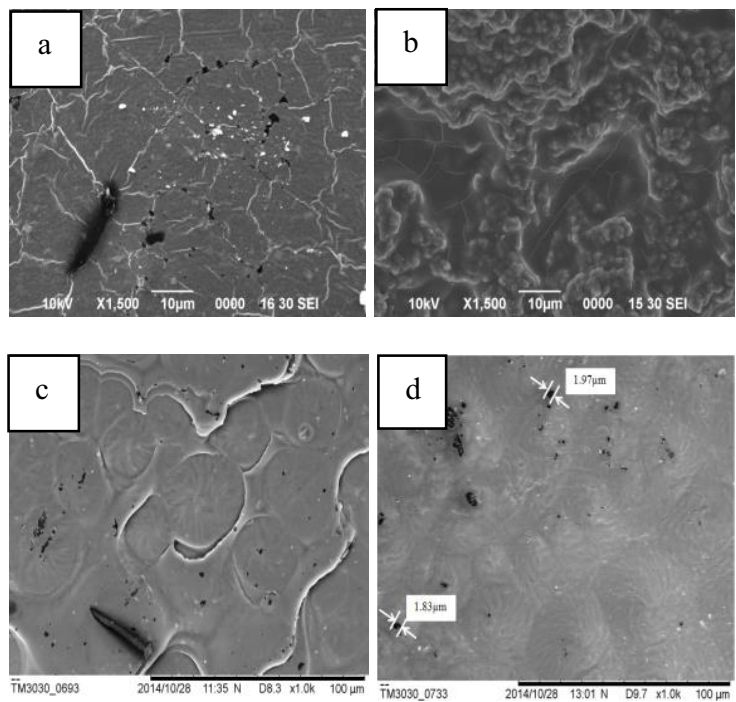

Figure 2. SEM micrographs of (a) PVA/fsi/clay (1.28E) nanocomposite, (b) PVA/fsi/clay (1.30E) nanocomposite, (c) PLA/fsi/clay (1.28E) nanocomposite and (d) PLA/fsi/clay (1.30E) nanocomposite.

\subsection{Tensile Properties}

The tensile strength and tensile modulus of PVA/fsi/clay and PLA/fsi/clay nanocomposites were shown in Figure 3 and 4 respectively. From Figure 3, $\mathrm{PVA} /$ fsi/clay (1.30E) and PLA/fsi/clay (1.28E) nanocomposites had higher tensile strength comparatively. This was due to the addition of clay towards the PVA and PLA matrices that reduced the inter-particle distance which enhanced the tensile strength of the nanocomposites [22]. When the suitable clay was introduced, the agglomeration could be reduced and less pores to be formed that improved the tensile strength of the nanocomposites.

According to Figure 4, PVA/fsi/clay (1.30E) nanocomposite had higher tensile modulus compared to PVA/fsi/clay (1.28E) nanocomposite. This was because the clay $(1.28 \mathrm{E})$ contained trimethyl stearyl ammonium, which imparted anti-wetting property and cause the surface of PVA-si-clay (1.28E) nanocomposites to become hydrophobic [23]. 
The improvements in tensile strength and modulus were ascribed to the presence of clay nanoparticles. Clay nanoparticles provided good compatibility and interfacial bonding strength toward PVA/fsi and PLA/fsi matrices. In addition, a stable hindrance layer was formed between clay particles which inhibited the agglomeration and thus improved the dispersion of the clay within PVA/fsi and PLA/fsi matrices [24].

Overall, tensile properties proved that clay (1.28E) was well introduced into PLA/fsi matrix while clay (1.30E) was well intercalated with PVA/fsi matrix. The outcome of the better compatibility of the nanocomposites was reflected in the thermal stability as well as surface morphology.

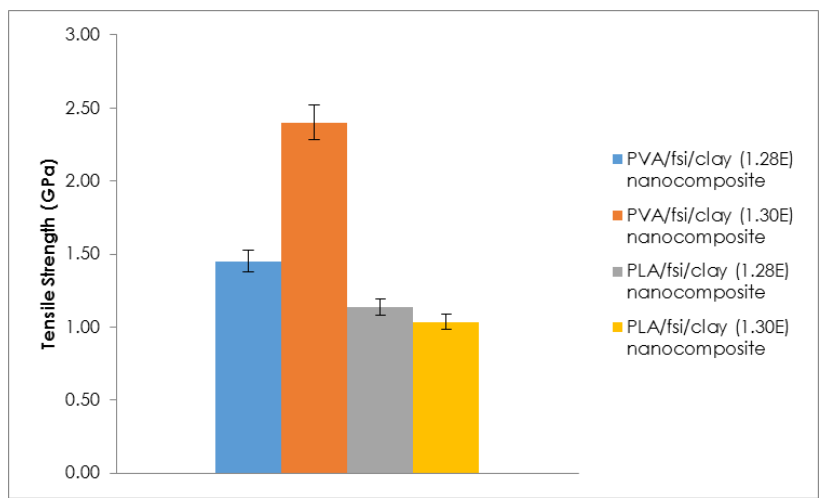

Figure 3. Tensile strength of PVA/fsi/clay and PLA/fsi/clay nanocomposites.

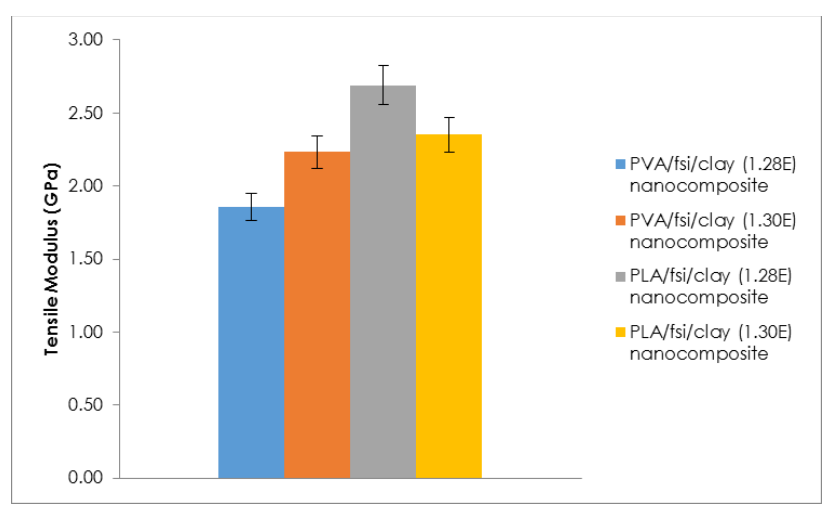

Figure 4. Tensile modulus of PVA/fsi/clay and PLA/fsi/clay nanocomposites.

\subsection{Thermogravimetric analysis (TGA)}

The thermal stability of PVA/fsi/clay and PLA/fsi/clay nanocomposites was shown in Figure 5. Different types of clay led to different weight loss as there was a restriction in polymer chain mobility and suppression of decomposition. The clay and silica are well intercalated with polymer matrix by covalent bonds that prevented complete decomposition of the nanocomposites [25].

According to the TGA thermographs, the weight percent loss for the first step degradation was about 5\% for PVA/fsi/clay (1.28E) and PVA/fsi/clay (1.30E) nanocomposites, respectively due to the removal of moisture. The second step degradation occurred with the weight loss of $7 \%$ for PVA/fsi/clay nanocomposites. The final degradation weight loss was $1.5 \%$ and $1.3 \%$ for $\mathrm{PVA} /$ fsi/clay (1.28E) and PVA/fsi/clay (1.30E) nanocomposites, respectively. The bonding compatibility of PVA/fsi and clay (1.28E) was higher than clay $(1.30 \mathrm{E})$ as proven by tensile strength and modulus.

From Figure 5, the first step degradation of PLA/fsi/clay nanocomposites occurred at 200 while the second step degradation occurred at 350 . PLA/fsi/clay (1.28E) nanocomposite exhibited a small weight percent loss of $3.8 \%$ below 300 as the absorbed water on the surface of the nanocomposites was removed. At second stage, PLA/fsi/clay (1.28E) nanocomposite showed higher weight percent loss (12.05\%) compared to PLA/fsi/clay (1.30E) nanocomposites. The improved thermal stability of PLA/fsi/clay (1.28E) nanocomposite was attributed to the clay acting as crosslinking agent that retarded the motion of polymer chain [26].

The activation energy can be helpful in reaching conclusions about the thermal stability of PVA-si-clay nanocomposites. The Arrhenius equation was used to determine the activation energy [27], which was summarized in Table 2. It was found that the activation energy of PVA/fsi/clay (1.30E) and PLA/fsi/clay (1.28E) nanocomposites wre significantly higher than $\mathrm{PVA} /$ fsi/clay (1.28E) and PLA/fsi/clay (1.30E) nanocomposites. The higher activation energy implied better thermal stability. Overall, the incorporation of clays especially clay (1.28E) and clay (1.30E) into $\mathrm{PLA} / \mathrm{fsi}$ and PVA/fsi matrices successfully improved thermal stability of $\mathrm{PVA} / \mathrm{fsi} / \mathrm{clay}$ and $\mathrm{PLA} / \mathrm{fsi} /$ clay nanocomposites that were reflected in other results.

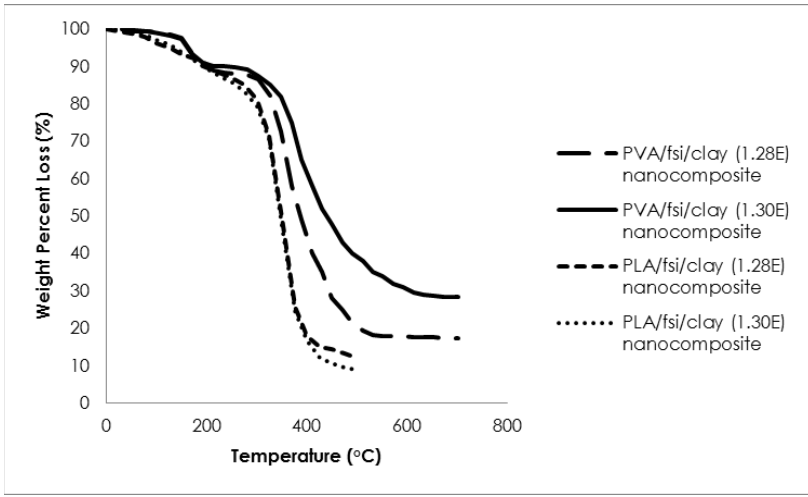

Figure 5. TGA curves of PVA/fsi/clay and PLA/fsi/clay nanocomposites.

Table 2. Activation energy of PVA/fsi/clay and PLA/fsi/clay nanocomposites.

\begin{tabular}{|c|c|c|c|c|}
\hline Samples & $\begin{array}{c}\text { PVA/fsi } \\
\text { /clay } \\
\mathbf{( 1 . 2 8 E})\end{array}$ & $\begin{array}{c}\text { PVA/fsi } \\
\text { /clay } \\
\mathbf{( 1 . 3 0 E})\end{array}$ & $\begin{array}{c}\text { PLA/fsi } \\
\text { /clay } \\
\mathbf{( 1 . 2 8 E})\end{array}$ & $\begin{array}{c}\text { PLA/fsi } \\
\text { /clay } \\
\mathbf{( 1 . 3 0 E )}\end{array}$ \\
\hline $\mathrm{T}_{\mathrm{i}}\left({ }^{\circ} \mathrm{C}\right)^{\mathrm{a}}$ & 280.0 & 303.0 & 108.9 & 103.2 \\
\hline
\end{tabular}




\begin{tabular}{|c|c|c|c|c|}
\hline $\mathrm{T}_{\mathrm{m}}\left({ }^{\circ} \mathrm{C}\right)^{\mathrm{b}}$ & 347.0 & 431.0 & 316.6 & 304.0 \\
\hline $\mathrm{T}_{\mathrm{f}}\left({ }^{\circ} \mathrm{C}\right)^{\mathrm{c}}$ & 410.0 & 511.0 & 421.1 & 418.1 \\
\hline $\mathrm{W}_{\mathrm{Ti}}\left({ }^{\circ} \mathrm{C}\right)^{\mathrm{d}}$ & 89.1 & 86.0 & 96.2 & 97.9 \\
\hline $\mathrm{W}_{\mathrm{Tm}}\left({ }^{\circ} \mathrm{C}\right)^{\mathrm{e}}$ & 66.0 & 52.0 & 80.4 & 79.4 \\
\hline $\mathrm{W}_{\mathrm{Tf}}\left({ }^{\circ} \mathrm{C}\right)^{\mathrm{f}}$ & 43.5 & 38.0 & 15.2 & 12.2 \\
\hline $\mathrm{E}_{\mathrm{a}}$ & 25.574 & 31.660 & 6670.5 & 5523.5 \\
\hline
\end{tabular}

${ }^{\text {a }}$ Temperature corresponding to the maximum rate of mass loss

${ }^{\mathrm{b}}$ Temperature corresponding to the beginning of decomposition

${ }^{c}$ Temperature corresponding to the end of decomposition

${ }^{\mathrm{d}}$ Mass loss at temperature corresponding to the maximum rate of mass loss

${ }^{\mathrm{e}}$ Mass loss at temperature corresponding to the beginning of decomposition

f Mass loss at temperature corresponding to the end of decomposition

$\mathrm{E}_{\mathrm{a}}$ Activation Energy $(\mathrm{kJ} / \mathrm{mol})$

\section{CONCLUSION}

PVA/fsi/clay and PLA/fsi/clay nanocomposites were prepared via solution intercalation and solutionintercalation film-casting. The resultant nanocomposites were characterized by FT-IR, SEM, tensile test and TGA. The reduction of hydroxyl group and the dispersion of clay for PVA/fsi/clay nanocomposites were confirmed by FT-IR spectroscopy. Besides, FT-IR spectrum indicated that PLA/fsi/clay (1.28E) nanocomposite showed broader peaks (especially the vibration of $\mathrm{C}-\mathrm{O}-\mathrm{C}$ group confined by silica network) than $\mathrm{PLA} /$ fsi/clay (1.30E) nanocomposite. The uniform surface of $\mathrm{PVA} / \mathrm{fsi} /$ clay (1.30E) and PLA/fsi/clay (1.28E) nanocomposites indicated better compatibility among the matrices with clay. Higher mechanical properties were found in $\mathrm{PVA} /$ fsi/clay (1.30E) and $\mathrm{PLA} / \mathrm{fsi} /$ clay (1.28E) nanocomposites compared to others nanocomposites. TGA result revealed that the thermal stability with higher activation energy of PVA/fsi/clay (1.30E) and $\mathrm{PLA} /$ fsi/clay (1.28E) nanocomposites were significantly improved.

\section{Acknowledgement}

The authors would like to acknowledge the financial support from COERE Fund with Grant no. COERE/GRANT/2013/06

\section{References}

1. R. Solaro, A. Corti, E. Chiellini, Polym. Adv. Technol. 11, 873-878 (2010)

2. E. Chiellini, A. Corti, S. D'Antone, R. Solaro, Prog. Polym. Sci. 28, 963-1014 (2003)

3. R.E. Drumright, P.R. Gruber, D.E. Henton, Adv. Mater. 12, 1841-1846 (2000)
4. N.N. Chaloupi, Development of Polylactide-clay nanocomposites for food packaging applications (University of Montreal, Canada, 2011)

5. M. Conradi, Mater. Technol. 47, 285-293 (2013)

6. R.T. Yang, N. Tharappiwattananon, R.Q. Long, J. Appl. Catalyst B. Environ. 19, 289-304 (1998)

7. J.H. Chang, T.G. Jang, K.J. Ihn, W.K. Lee, G.S. Sur, J. Appl. Polym. Sci. 90, 3208-3214 (2003)

8. A.A. Sapalidis, F.K. Katsaros, Th.A. Steriotis, N.K. Kanellopoulos, J. Appl. Polym. Sci. 123, 1812-1821 (2012)

9. Z. Peng, L.X. Kong, Polym. Degrad. Stabil. 92, 1061-1071 (2007)

10. J. Zhang, J. Lou, S. Ilias, P. Krishnamachari, Polym. 49, 2381-2386 (2008)

11. A.R. McLauchlin, N.L. Thomas, Polym. Degrad. Stabil. 94, 868-872 (2009)

12. S.M. Lai, Y.T. Hsieh, Journal of Macromolecular Science, Part B: Physics. 55, 211-228 (2016)

13. J.C.H. Lai, M.R. Rahman, S. Hamdan, F.K. Liew, M.M. Rahman, M.F. Hossen, J. Appl. Polym. Sci. 132 (2015)

14. J.C.H. Lai, M.R. Rahman, S. Hamdan, Int. J. Polym. Sci. 2015 (2015)

15. S. Mansur Herman, L. Orefice Rodrigo, A.P. Mansur Alexandra, Polym. 45, 7193-7202 (2004)

16. A.P.V. Perrira, W.L. Vasconcelis, L. Orefice Rodrigo, J. Non-Crystalline Solids. 273, 180185 (2000)

17. M. Liu, Y. Zhang, C. Zhou, Appl. Clay Sci. 7576, 52-59 (2013)

18. S. Bocchini, K. Fukushima, A. Di Blasio, A. Fina, A. Frache, F. Geobaldo, Biomacromol. 11, 2919-2926 (2010)

19. E. Kontou, M. Niaounakis, P. Georgiopoulus, J. Appl. Polym. Sci. 122, 1519-1529 (2011)

20. Y. Luo, Y. Zhao, Y. Cai, S. Du, Mater. Des. 33, 405-412 (2012)

21. I.R. Mustapa, R.A. Shanks, I. Kong, Int. J. Adv. Sci. Eng. Technol. 3, 192-199 (2013)

22. K. Nakane, T. Yamashita, K. Iwakura, F. Suzuki, J. Appl. Polym. Sci. 74, 133-138 (1999)

23. K.M. Seeni Meera, R. M. Sankar, A. Murali, S.N. Janiskar, A.B. Mandal, Colloid. Surfaces B Biointerf. 90, 204-210 (2012)

24. Y. Zheng, Y. Zheng, R. Ning, Mater. Lett. 57, 2940-2944 (2003)

25. X. Jia, Y. Li, Q. Cheng, S. Zhang, B. Zhang, Eur. Polym. J. 43, 1123-1131 (2007)

26. R. Benlikaya, M. Alkan, I. Kaya, Polym. Compos. 30, 1585-1594 (2009)

27. C.V. Chanmal, J.P. Jog, eXPRESS Polym. Lett. 2, 294-301 (2008)

28. Luigi T.De Luca, Propulsion physics (EDP Sciences, Les Ulis, 2009)

29. F. De Lillo, F. Cecconi, G. Lacorata, A. Vulpiani, EPL, 84 (2008) 